\title{
Safety Separation Assessment Based on GBAS Landing System
}

\author{
Bo Liang, Xu Li and Zhiyuan Shen \\ College of Civil Aviation, Nanjing University of Aeronautics and Astronautics, Nanjing, China, 210016
}

\begin{abstract}
In order to meet the continuous growth of air traffic flow in the future, it is important to reduce the aircraft separation to ensure the efficiency and safety operation of air transportation. In this paper, collision risk model is used to study the safety flight separation under the condition of ground-based augmentation system (GBAS) Landing System. This model considers the positioning error of communication, navigation and surveillance of GLS respectively. It also analyze and calculate the available values of minimum safety separation in different speeds under various flight stages. The simulation results provide a reasonable recommendations for the future use of GLS in the world.
\end{abstract}

Keywords-air traffic management; GLS; collision risk model; safety separation

\section{INTRODUCTION}

With the continuous development of air traffic transportation, air traffic flow is growing every day. How to meet the safety and operational efficiency requests of flights in limited airspace become the significant issue in the future development of Chinese civil aviation. As a result, reducing flights safety separation is the focal point to solve this problem. International Civil Aviation Organization (ICAO) and its Contracting States and relevant international organizations are committed to researching new technologies in this investigation field, to meet the demands of air traffic management in the future. At present, Performance Based Navigation (PBN) has been identified as the primary direction of development for the future navigation system. The implementation of this technology depends on the establishment of the Global Navigation Satellite System (GNSS). Due to the large error in the use of GNSS, the Global Positioning System (GPS) performance is enhanced in every country, in order to meet the requirement of the accuracy and completeness of GNSS positioning in civil aviation operation, including the GroundBased Augmentation System (GBAS). Compared with the existing Instrument Landing System (ILS), GBAS Landing System (GLS) which is developed by GBAS can meet the requirements of multi-runway and multi-approach procedures, and has the operational advantages of low requirements of facilities and environment, signal stability, better navigation performance, shorten the air route, improving safety quality, low cost of construction and operation and flexible use. Now it has been the current development target and tried to use in the International Civil Aviation Organization (ICAO) and some civil aviation developed countries. The development of Ground-Based Augmentation System is in accordance with the requirement of China's 13th plan of five - year national development in establishing civil aviation power and is a substantial help for the China's traffic upgrade in the limited airspace. In the future, the development of navigation and operation is bound to become a hot research direction.

GBAS Landing System (GLS) is a ground-based augmentation precision approach landing system based on satellite navigation. It is mainly composed of ground-based augmentation system, satellite-based augmentation system and airborne system. Ground-based augmentation system is composed of two or more GPS receivers, a data processor and a horizontally polarized VDB antenna. GLS works through the airborne system to plan a navigation localizer and glide path independently, according to the high-precision FAS data block with aircraft parameters sent by GBAS to correct the flight path, in order to achieve performance-based self-navigation and approach. In addition, GBAS will sent final approach path, horizontal and vertical limited alerting, atmosphere data model and other information uniformly to the airborne receiver. As of June 2015, about 25 airports around the world are using the system. At present, only China's Shanghai Pudong international airport completed the operation of GLS verification. The progress involved the regional management administration of the Civil Aviation Administration, air traffic control departments, airports, airlines, GBAS equipment manufacturer Honeywell, aircraft production manufacturers, design companies and dozens of other units and departments. They invested a lot of manpower and resources and spent several years to verify the flight to be successful. For the future, the development of GLS in China still has a long way to go. In addition, with the ongoing development of China's Beidou navigation system, part of GPS navigation's function will be gradually replaced in the near future. Compared with the standby work style of using ground equipment to measure difference of degree of modulation of instrument landing system, GLS is flexible to install, saves frequency resources and has accuracy ranging, the ability of anti-interference, faster approach speed and other advantages. In actual operation, the use of GLS system can greatly reduce the separation between two aircraft.

At present, many scholars both domestic and overseas established collision risk model to achieve the purpose of assessment the separation of flight safety. Evaluating the security separation under the GLS condition can greatly facilitate the application progress of GLS in the actual operation.

Some aviation developed countries in Europe and the United States began the theoretical research of safety 
separation in 1960s. The most famous in those results is the Collision Risk Model in the direction of longitudinal, lateral and vertical in North Atlantic route system [1] established by British scholar Reich. Then Peter Brooker established the EVENT collision risk model in longitudinal and lateral separation [2]. In the respect of GLS, foreign scholars through many simulations and calculations of the satellite-based landing system in parallel runway, structured the system and established a relatively complete system of theory and operation in positioning difference and operation condition. In 1998, Pederson and McCall proposed the design idea and framework of the satellite-based landing system in accordance with the provisions of the FAA [3]. In 2011, Ferdinand Behrend combined the operation results of GLS under the condition of CAT I, proposed the GLS flight operation requirements under CAT II and provided a theoretical basis for a higher development of GLS [4]. In 2013, Felax and Dautermann showed the performance of GLS in actual operational and obtained the advantages compared with ILS system [5]. In 2014, Jeong obtained the horizontal and vertical deviation range based on the GLS test operation data of Gimpo Airport in Korea. Through comparison with ILS, he obtained that GLS is much better in precision and can fully meet the requirements of CAT II [6]. Domestically, in 2010, Xu Shaohao, Zhao Hongsheng and Wang Zhenyu have studied, compared and analyzed the reduce technique of wake separation [7]. In 2012, Li Bin, who analyzed the GBAS test flight date in domestic airport and evaluated the performance of GBAS ground system considered whether the GBAS system can meet the precision requirements of CAT I approach and landing standards for navigation system [8]. In 2014, Liu Ruihua studied and simulated the Beidou satellite and evaluated whether the performance of it can meet the requirements of GLS precision approach and landing requirements at Tianjin Binhai airport [9]. In 2016, Yu Geng established the mathematical model and analyzed the flight path of approaching and landing with the data comparison of GLS and ILS approach in the same coordinate system, calculated the error rate of two different navigation methods and standard track and obtained the approach strategy of GLS [10].

This paper mainly adopts the collision risk model, considering the influence of communication, navigation and surveillance errors on flight safety separation under the condition of GLS. In this paper, we first establish the REICH model of GLS positioning deviation at the same height and then evaluate the collision risk under different situation. Next, we obtain the value of collision risk applied for different types of aircraft. Thirdly, the probability of collision risk is calculated by Matlab program. Finally we analyze the safety separation of different types of aircraft which are using GLS approach system and further considerate the factors affecting collision probability. From the collision risk and operation separation, this paper provides a feasible theoretical basis for the realization of GLS approach.

\section{COLLISION RISK MODEL}

Take two aircraft flying at the same altitude as an example, $D_{1}$ is the horizontal separation between aircraft $(i, j)$, the planes are effected of by the GLS environment conditions, including positioning errors of navigation, communication, surveillance, which three caused the aircraft positioning tolerance. The tolerance is the minimum margin of safety required in order to keep the aircraft operating. For the determination of positioning error, the positioning tolerance $X_{i} 、 X_{j}$ of aircraft $(i, j)$ caused by communication, navigation and surveillance error obeys the normal distribution with mean value of zero.

That is to say, the positioning error of the aircraft $i$ is:

$$
X_{i(C, N, s)} \sim N\left(0, \sigma^{2}\right)
$$

The positioning error of the aircraft $j$ is:

$$
X_{\mathrm{j}(C 、 N 、 S)} \sim N\left(0, \sigma^{2}\right)
$$

When the time is infinitely close to zero, the horizontal separation of the two aircraft is

$$
D_{2}=D_{1}+X_{1}-X_{2}
$$

("+" is for the left aircraft and "-" is for the right aircraft)

So:

$$
D_{2}-D_{1} \sim N\left(0, \sigma_{1}^{2}+\sigma_{2}^{2}\right), \frac{D_{2}-D_{1}}{\sqrt{\sigma_{1}^{2}+\sigma_{2}^{2}}} \sim N(0,1)
$$

According to the collision model theory, when the separation between two aircraft is less than the shape data $S$ ( $S=\max$ (Aircraft Length \& Wing span Length)) of the two aircraft, it is considered that there is a collision. Therefore, the collision probability of two aircraft is:

$$
P\left(\left|D_{2}\right|<L\right)=P\left(-L<D_{2}<L\right)=\Phi\left(\frac{D_{1}+L}{\sqrt{\sigma_{1}^{2}+\sigma_{2}^{2}}}\right)-\Phi\left(\frac{D_{1}-L}{\sqrt{\sigma_{1}^{2}+\sigma_{2}^{2}}}\right)
$$

Therefore, in order to obtain the collision probability of aircraft, it is necessary to determine the positioning error and the positioning error of the two planes according to the performance parameters of GLS.

\section{DETERMINATION OF GLS PARAMETERS}

GLS is a subdivision of Performance Based Navigation $(\mathrm{PBN})$. PBN can divided into Required Navigation Performance (RNP), Required Communication Performance (RCP) and Required Surveillance Performance (RSP). During approach, different navigation stages correspond to different GLS performance parameters.

RNP refers to the navigation performance accuracy required by an aircraft in a certain route, airspace or region, and is described by accuracy. 
TABLE I. RNP PARAMETER TABLE

\begin{tabular}{|c|c|c|}
\hline $\begin{array}{c}\text { Required } \\
\text { performance }\end{array}$ & $\begin{array}{c}\text { Positioning } \\
\text { accuracy }(\mathbf{n m})\end{array}$ & Applicable scope \\
\hline RNP APCH & 0.3 & Final approach stage \\
\hline RNP 1/2 & 0.5 & $\begin{array}{c}\text { SID, STAR, route, and the } \\
\text { flight before final approach } \\
\text { point }\end{array}$ \\
\hline RNP 4 & 4 & $\begin{array}{c}\text { RNAV and route flight } \\
\text { (available for cross water } \\
\text { operation) }\end{array}$ \\
\hline RNP 5 & 5 & $\begin{array}{c}\text { En-route flight(only on } \\
\text { land) }\end{array}$ \\
\hline
\end{tabular}

RCP usually described in terms of time, continuity, and completeness.

TABLE II. RCP PARAMETER TABLE

\begin{tabular}{|l|c|c|c|c|}
\hline $\begin{array}{c}\text { Required } \\
\text { performa } \\
\text { nce }\end{array}$ & $\begin{array}{c}\text { Positioning } \\
\text { accuracy } \\
\text { (nm) }\end{array}$ & $\begin{array}{c}\text { Continui } \\
\text { ty }\end{array}$ & $\begin{array}{c}\text { Availabili } \\
\text { ty }\end{array}$ & $\begin{array}{c}\text { Complete } \\
\text { ness }\end{array}$ \\
\hline RCP 10 & 10 & 0.995 & 0.99998 & $10^{-5}$ \\
\hline RCP 60 & 60 & 0.99 & 0.9995 & $10^{-5}$ \\
\hline RCP 120 & 120 & 0.99 & 0.9995 & $10^{-5}$ \\
\hline RCP 240 & 240 & 0.99 & 0.9995 & $10^{-5}$ \\
\hline RCP 400 & 400 & 0.99 & 0.999 & $10^{-5}$ \\
\hline
\end{tabular}

RSP refers to the ability to obtain aircraft parameters in a given precision and refresh rate, with time description.

TABLE III. RNP PARAMETER TABLE

\begin{tabular}{|c|c|c|}
\hline $\begin{array}{c}\text { Required } \\
\text { performance }\end{array}$ & Refresh rate & Reaction time \\
\hline RSP 20 & $\leq 20 \mathrm{~s}$ & $2 \mathrm{~s}$ \\
\hline RSP 10 & $\leq 10 \mathrm{~s}$ & $2 \mathrm{~s}$ \\
\hline RSP 5 & $\leq 5 \mathrm{~s}$ & $2 \mathrm{~s}$ \\
\hline
\end{tabular}

Let $\mathrm{A}$ be the navigation error parameter, the unit is nautical mile (nm); B is communication error parameter, unit is second (s); C is surveillance error parameter, unit is second (s). They correspond to the accuracy values of RNP, RCP and RSP respectively. Under the condition of GLS, the Required Navigation Performance can meet the RNP APCH condition, so the RNP positioning accuracy is 0.3 nautical miles; Required Communication Performance can meet the RCP 10, RCP communication error is 10 seconds; the Required Surveillance Performance can meet the RSP 5, RSP surveillance error is 5 seconds, so:

$$
A=0.3 n m \quad B=10 \mathrm{~s} \quad C=5 \mathrm{~s}
$$

We can obtain from the integration of the normal distribution of the horizontal position error of the aircraft:

$$
\begin{aligned}
& \int_{-a}^{a} \frac{1}{\sqrt{2 \pi} \sigma_{1}} \exp \left(\frac{x^{2}}{2 \sigma_{1}^{2}}\right) d x=0.95 \\
& \int_{-b v}^{b v} \frac{1}{\sqrt{2 \pi} \sigma_{2}} \exp \left(\frac{x^{2}}{2 \sigma_{2}^{2}}\right) d x=0.95 \\
& \int_{-c v}^{c v} \frac{1}{\sqrt{2 \pi} \sigma_{3}} \exp \left(\frac{x^{2}}{2 \sigma_{3}^{2}}\right) d x=0.95
\end{aligned}
$$

$\sigma_{1} \sigma_{2} \sigma_{3}$ are the horizontal position errors of navigation, communication and surveillance, we can obtain from the three formulas below:

$$
\begin{gathered}
2 \Phi\left(a / \sigma_{1}\right)-1=0.95 \\
2 \Phi\left(b v / \sigma_{2}\right)-1=0.95 \\
2 \Phi\left(c v / \sigma_{3}\right)-1=0.95
\end{gathered}
$$

The solution is:

$$
2 \Phi\left(a / \sigma_{1}\right)-1=0.95
$$

$$
\begin{aligned}
& 2 \Phi\left(b v / \sigma_{2}\right)-1=0.95 \\
& 2 \Phi\left(c v / \sigma_{3}\right)-1=0.95
\end{aligned}
$$

So the horizontal position error of flights is:

$$
\sigma=\sqrt{\sigma_{1}^{2}+\sigma_{2}^{2}+\sigma_{3}^{2}}=\sqrt{0.2603\left(a^{2}+b^{2} v^{2}+c^{2} v^{2}\right)}
$$

Combined with the collision risk probability model, the risk probability is:

$$
\begin{array}{r}
P=\Phi\left(\frac{D_{1}+L}{\sqrt{0.2603\left[2 a^{2}+\left(b^{2}+c^{2}\right)\left(v_{1}^{2}+v_{2}^{2}\right)\right]}}\right) \\
-\Phi\left(\frac{D_{1}-L}{\sqrt{0.2603\left[2 a^{2}+\left(b^{2}+c^{2}\right)\left(v_{1}^{2}+v_{2}^{2}\right)\right]}}\right)
\end{array}
$$

\section{EXAMPLE ANALYSIS}

Suppose that two Airbus A320-200 planes at the same altitude and approaching with the GLS system, and remain the 
same speed. A320-200 is 37.57 meters long and the length of wingspan is 34.09 meters, so take $\mathrm{L}=37.57 \mathrm{~m}=0.0203 \mathrm{~nm}$.

RNP navigation error value in the GLS is $0.3 \mathrm{~nm}$, so the transmission performance of $A=0.3 \mathrm{~nm}$; at present the link transmission performance used for the airborne separation assurance system can meet the requirement of RCP10, so the value of $B$ is $10 \mathrm{~s}$, converted into hours, $B=1 / 360$ h. Currently surveillance system ADS-B refresh rate is $1 \mathrm{~s}$ and can reach the requirement of RCP10, so the value of $\mathrm{C}$ is $5 \mathrm{~S}$, converted into hours, $\mathrm{C}=1 / 720 \mathrm{~h}$.

The standard deviation of the normal distribution of the model is:

$$
\begin{aligned}
\sigma & =\sqrt{\sigma_{1}^{2}+\sigma_{2}^{2}+\sigma_{3}^{2}} \\
& =\sqrt{0.2603 \times\left(0.3^{2}+\frac{1}{360^{2}}\right) \times v^{2}+\frac{1}{720^{2}} \times v^{2}}
\end{aligned}
$$

Through the simulation of Matlab progrem, taking the probable speed of two aircraft on the same altitude into the procedure, the separation of two aircraft D1 begins from $1 \mathrm{~nm}$ and adds $0.01 \mathrm{~nm}$ per step, solving each collision probability and choses the value less than $5 \times 10^{-9}$ as the safety separation, the obtained simulation results are as follows:

TABLE IV. RNP PARAMETER TABLE

\begin{tabular}{|c|c|c|c|}
\hline \multicolumn{2}{|c|}{ Speed(knots) } & \multirow{2}{*}{$\begin{array}{c}\text { Safety Separation } \\
(\text { nm })\end{array}$} & Collision Probability \\
\cline { 1 - 2 } $\boldsymbol{V}_{\boldsymbol{1}}$ & $\boldsymbol{V}_{\boldsymbol{2}}$ & 5.71 & $4.96033 \times 10^{-09}$ \\
\hline 460 & 460 & 4.97 & $4.73057 \times 10^{-09}$ \\
\hline 460 & 320 & 4.07 & $4.87414 \times 10^{-09}$ \\
\hline 320 & 320 & 3.69 & $4.66024 \times 10^{-09}$ \\
\hline 320 & 250 & 3.25 & $4.88798 \times 10^{-09}$ \\
\hline 250 & 250 & & \\
\hline
\end{tabular}

Choosing the speed of two aircraft as 250 knots as an example, this is the relation figure of collision probability and flight separation:

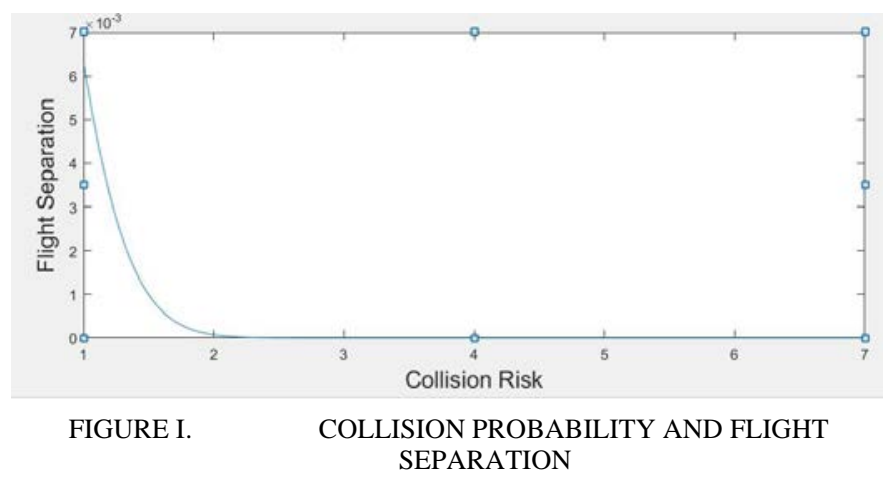

Combined with the above chart and table, under the condition of GLS approach, the greater speed of two aircraft and the more security separation in the case of ensuring the probability of collision required is needed. When the aircraft speed is constant, with the aircraft separation increasing, the collision probability of two aircraft is reduced.

\section{CONCLUSION}

In this paper, we started with the aircraft collision risk model and introduce the three control elements of communication, navigation and surveillance to determine the aircraft horizontal position error. Then we used relevant models and simulation operations to ensure the effectiveness and feasibility of the results. Through this idea, this paper draws the minimum safety separation and collision risk of aircraft for different flight speed under GLS condition, providing some theoretical guidance for GLS to be used for practical operation from the perspective of safety and operation.

\section{ACKNOWLEDGMENT}

The authors would like to thank the financial support by China Postdoctoral Science Foundation funded project (2016M601806), Jiangsu Province Postdoctoral Science Foundation funded project and College Students' Free Exploration Program (ZT2016061) of Nanjing University of Aeronautics and Astronautics.

\section{REFERENCES}

[1] REICH P G. Analysis of long-range air traffic systems;separation standards-III[J]. Journal of the Institute of Navigation,1966,19(3),331347

[2] Peter Brooker,longtitudinal collision risk for ATC track systems: a hazardous event model[J]. Journal of Navigation,2006,59(1):55-70.

[3] Barbara A.Pederson, Daryl L.McCall. Collins GLS architecture for regional and business aircraft[J]. IEEE,1997 : 6.1-16-6.1-22.

[4] Ferdinand Behrend, Oliver Lehmann, Technische Universität Berlin TUB, Berlin, Germany David De Smedt, Sylvie Grand-Perret, eurocontrol, Brussels, Belgium. CAT II / OTS CAT II operations using existing CAT I ground based augmentation system[J]. IEEE, 2011 : 4B2-1-4B2-11.

[5] Dieter Guenter, Joseph Dennis, Pragmatics Inc., Reston, Virginia. Initial operational experience with CAT I ground based augmentation system (GBAS)[J]. IEEE,2015: S1-1-S1-15.

[6] Myeong-Sook Jeong, Joongwon Bae,Hyang-Sig Jun,Young Jae Lee. Flight test evaluation of ILS and GBAS performance at Gimpo International Airport[J]. GPS Solut,2016 (20) :473-483.

[7] Xu Xiaohao, Zhao Hongsheng, Wang Zhenyu. Review of wake space reduction techniques, [J]. Journal of Aeronautics and aerospace, 2010, 31 (4): 655-662.

[8] Li Bin, Wang Xiaowang, Hu Gang. Flight test analysis of ground-based augmentation system (GBAS) [J]. modern navigation, 2012, 03 (1): 6-9.

[9] Liu Ruihua, Jiang Yuqi. Beidou GLS integrity monitoring simulation [J]. proceedings of the National Conference on signal and intelligent information processing and application, 2014.

[10] Zong Ping, Lu Shao Yong, Zhong Congjiu. Based on satellite instrument landing system approach combination strategy of [J]. science technology and engineering, 2016, 16 (11): 104-109. 